\title{
Salud y enfermedad: realidad y metáfora. La ampliación del lenguaje científico a partir del siglo XIII. El caso de la medicina
}

\section{Health and Disease: Reality and Metaphor. Scientific Language's Development as of 13th Century. The case of Medicine}

\author{
Celina A. Lértora Mendoza \\ Conicet, Buenos Aires \\ fundacionfepai@yahoo.com.ar
}

El propósito de este trabajo es una reconstrucción histórico-crítica de las modificaciones epistemológicas producidas a partir de comienzos del siglo XIII con la recepción del corpus greco-árabe. La concepción aristotélica del conocimiento científico influyó significativamente en la ampliación del horizonte lingüístico técnico y en la constitución de las disciplinas tardomedievales.

Se pone el acento en exhibir la mentalidad receptora en su aspecto gnoseológico: se modifican las formas expositivas de las obras científicas recibidas hasta el siglo XII conforme a un concepto de ordo veritatis y no de verdades aisladas; además se afirma la forma deductivista de justificación epistemológica.

Desde el punto de vista del lenguaje científico, se aprecian las siguientes novedades: 1. el uso metafórico del lenguaje descriptivo, 2. asignación de valor descriptivo (para el conocimiento científico en sentido aristotélico) del lenguaje metafórico. Esto se aprecia en dos géneros relevantes en la época. Las traducciones usan recursos que se estandarizan: transliteración, metáfora y neologismo. Los comentarios: incluyen estos temas en diversos marcos temáticos. Se ilustra con el caso del lenguaje médico en el Commentarius in Octo Physicorum de Roberto Grosseteste.

Palabras Clave: epistemología medieval, lenguaje científico-médico, Roberto Grosseteste

The purpose of this work is a historical-critical reconstruction of the epistemological modifications produced from the beginning of the thirteenth century with the reception of the Greek-Arab corpus. The Aristotelian conception of scientific knowledge significantly influenced the broadening of the technical linguistic horizon and the constitution of the late medieval disciplines.

The accent is placed on exhibiting the receptive mentality in its epistemological aspect: the expository forms of the scientific works received until the twelfth century are modified according to a concept of ordo veritatis and not of isolated truths; it also affirms the deductivist form of epistemological justification. 
From the point of view of scientific language, the following novelties are appreciated: 1 . the metaphorical use of descriptive language, 2. assignment of descriptive value (for scientific knowledge in the Aristotelian sense) of metaphorical language. This is seen in two relevant genres at the time. The translations use resources that are standardized: transliteration, metaphor, and neologism. Comments: include these topics in various thematic frameworks. It is illustrated with the case of medical language in the Commentarius in Octo Physicorum by Roberto Grosseteste.

KeYwORDS: medieval epistemology, scientific-medical language, Roberto Grosseteste modificaciones epistemológicas producidas a partir de comienzos del siglo XIII con la recepción del corpus greco-árabe. La concepción aristotélica del conocimiento científico influyó significativamente en la ampliación del horizonte lingüístico técnico y en la constitución de las disciplinas tardomedievales. Ilustraré este proceso con el caso de la medicina, un saber bastante desarrollado por la tradición monacal, pero que a partir de esta época debe estructurarse conforme al modelo aristotélico de sistema científico.

Esta reconstrucción histórico-crítica consta de dos ejes conceptuales:

a) La significación propia del corpus, es decir, el material cognoscitivo que se incorporaba.

b) La asunción de este material, o sea, de qué modo y desde qué horizonte mental fue leído e interpretado, en las dos tareas fundamentales de esta época: las traducciones y los comentarios.

En este trabajo me centraré en el segundo punto, que considero tan esencial como el primero para la reconstrucción intentada.

\section{A. LA MENTALIDAD RECEPTORA}

El horizonte mental de comprensión de los nuevos datos abarca dos aspectos: la concepción del conocimiento y el lenguaje en su función descriptiva.

\section{A.I Aspecto gnoseológico}

El temprano siglo XIII heredaba del monacato y las escuelas del siglo XII un sustrato gnoseológico decantado a lo largo de varios siglos de influencia básicamente platónica y neoplatónica, a la que — en conjunto — no hizo mella la 
temprana crítica de orientación nominalista de Roscelino. Este sustrato, mirado más de cerca y en lo que nos interesa, muestra una adhesión generalizada, aunque difusa, a dos concepciones sobre el conocimiento y su relación con la realidad, que no han sido desarrolladas como doctrinas filosóficas propiamente dichas y aisladas del contexto teológico en que se movían los autores de los siglos XI y XII, pero que pueden ser claramente identificadas en ellos.

\section{A.I.1 El ejemplarismo platonizante}

Casi todos los teólogos-filósofos del Alto Medioevo se inclinaron hacia concepciones intuicionistas e iluminativistas del conocimiento, sea en seguimiento de Agustín, o en razón de su mayor facilidad de adaptación a los intereses espirituales de los teólogos, y también debido al escaso conocimiento del aristotelismo ortodoxo. Si consideramos la nómina de los grandes maestros latinos desde san Anselmo (que debe incluir a Gilberto de la Porrée, Guillermo de Champeaux, Adelardo de Bath, san Bernardo de Claraval, Guillermo de San Thierry, Hugo y Ricardo de San Víctor, Alano de Lila y Nicolás de Amiens) veremos que todos ellos, con la excepción de los tempranos nominalistas y de Pedro Abelardo, profesaron una gnoseología de tipo realista extrema y ejemplarista, en la cual se incluía también la consideración del carácter simbólico de la realidad empírica. Es cierto que las diferencias personales de estos maestros son significativas y nada desdeñables, lo cual impide hablar de una "doctrina" o "teoría" gnoseológica común. Pero sí es válido sostener la presencia de una gran corriente o dirección gnoseológica distinta — cuando no opuesta - al abstraccionismo aristotélico y que privilegiaba el carácter simbólico e indicial de la naturaleza. Bastaría mencionar uno de los últimos tratados pre-aristotelizantes en filosofía natural, el De planctu nuturae de Alano de Lila, ${ }^{1}$ expresión clásica del "naturalismo cristiano" del siglo XII, para comprender el universo mental con que se piensa la ciencia en esta época. Caracteres fundamentales de tal concepción son: el nexo entre naturaleza y divinidad (y por ende entre Filosofía como Ciencia y Teología), la realidad natural como plasmada según el ejemplar de las Ideas divinas y el sentido alegórico de las descripciones físicas.

\footnotetext{
${ }^{1}$ Migne, Patrología, t. 210. Esta obra es solidaria de otra que le provee del fundamento teológico, De fide catholica, redactada para refutar a los herejes desde la razón natural. La finalidad apologética de las obras incluso científicas fue algo no inusual en el siglo XII (entre los autores inclinados a este tipo de especulaciones también hallamos a Nicolás de Amiens) e inspirará todavía a los autores del siglo XIII. Lo importante para la historia de la ciencia es que marcan el inicio de un proceso de racionalización y sistematización de la tradición, con vistas a una exposición erga omnes (dirigida incluso a los herejes y no sólo a los cristianos).
}

Medievalia 50, 2018, pp. 299-314 
Este sustrato está presente, aunque no en forma explícita, en la metodología expositiva de las obras científicas del siglo XII, y que se inspiran, con mayor o menor fortuna, en las grandes enciclopedias de la antigüedad y la primera Edad Media, es decir, las Etimologías de Isidoro de Sevilla, el De rerum natura de Beda el Venerable y el De rerum naturis de Rabano Mauro (Gilson, La filosofía, 396). La suma de conocimientos del siglo XII que consta en el De imagine mundi $i^{2}$ de Honorio de Autun se articula en una visión teológica que parte de la creación y su arquetipo, pasa por la formación del mundo sensible de acuerdo con ese modelo, explica su desarrollo temporal y postula la renovación y recreación escatológica. Sin duda debe tenerse en cuenta que estas enciclopedias no son productos originales y creativos sino obras de enseñanza y divulgación, por lo cual no puede esperarse más de lo que este tipo de trabajos da de sí. Para nuestro cometido, no interesa señalar qué aciertos o errores contienen, sino qué tipo de mentalidad exhiben y cuáles formas de razonar y de estructurar datos usan. Me detendré brevemente en este aspecto, que es significativo.

El primer aspecto es la formulación del lenguaje descriptivo. Aquí apreciamos que la descriptividad se emparenta con la etimología, en el sentido de considerar a los nombres como auténticamente significantes de las naturalezas de las cosas, criterio que sólo es superable con una concepción convencional del lenguaje. La temprana Edad Media se guió por la idea del lenguaje esencial o natural, vinculada obviamente a las concepciones bíblicas. De allí el nexo entre la importancia concedida al nombre natural (que reemplaza a la cosa misma) y el recurso a la interpretación simbólica, que constituye el segundo aspecto de las particularidades del lenguaje descriptivo del siglo XII.

La interpretación simbólica consiste en tratar las cosas como signos cuya significación debe desentrañarse. En parte esta tendencia se debió a la finalidad moralizante de todos los autores, así trataran materias de zoología, botánica, geografía, astronomía, etc. De allí que en definitiva las realidades religiosas (Cristo, la Iglesia, la Salvación) sean las significaciones últimas de todo. Este simbolismo se completaba con el argumento analógico, del que tanto uso había hecho la tradición exegética alejandrina en la época de los Santos Padres. Hay que señalar que este tipo de argumentaciones de ningún

${ }^{2}$ Migne, Patrología, t. 172 al que sigue el De philosophia mundi (cols. 115-188) atribuido a Honorio pero que es de Guillermo de Conches. En esta línea habría que mencionar De natura rerum de Alejandro Neckahm (ed. en 1863 por M. Th. Wright en la colección Rerum Britannicarum Medii Aevi Scriptores, t. 34). La costumbre de redactar enciclopedias populares de este estilo se mantuvo en el siglo XIII. 
modo era errática o caprichosa, de acuerdo con los criterios de época, y que intentaba y presumía superar las exigencias de los dialécticos (lógicos) como Pedro Abelardo. Estas elaboraciones mentales no carecen de reglas precisas, sólo que ellas no se pueden identificar con los requisitos aristotélicos para las operaciones fundamentales de la ciencia, y este es el punto de crisis y fricción a partir del inicio del siglo XIII.

\section{A.I.2 El orden universal neoplatonizante}

En estrecha relación con la gnoseológia platonizante señalada, el Alto Medioevo coincidió en una peculiar visión, de origen alejandrino y neoplatónico, acerca de la correlación entre el orden veritativo y el orden real, solidaria con la concepción jerárquica del universo que los neoplátonicos habían entendido como emanación divina y que los pensadores religiosos (musulmanes, judíos y cristianos) corrigieron mediante el recurso de separar la cúspide jerárquica (Dios-Uno) mediante un "corte ontológico" que asegurara su absoluta trascendencia y su distinción esencial con toda criatura. Pero salvo este recaudo, la correlación ontognoseológica postulada por los neoplatónicos se mantuvo, como que también correspondía a la concepción ejemplarista ontológica que defendían los maestros religiosos desde la época patrística.

El resultado científico más significativo de esta asunción es asegurar que la coherencia interna de un sistema de conocimiento reproduce la realidad y permite el acceso a sus principios explicativos esenciales. No hay pues, "verdades" científicas aisladas, sino una "verdad" global asegurada por el ordo veritatis. Lejanos ecos de esta idea los veremos todavía a fines del siglo XIII en la obra de Bacon y su concepto de la unidad de la ciencia, ${ }^{3}$ probando que esta concepción podía compaginarse con una visión más empírica y deductivista (en sentido aristotélico) del trabajo científico.

\section{A.II Aspecto lingüístico}

El uso descriptivo del lenguaje altomedieval es sin duda solidario con las asunciones gnoseológicas mencionadas. Pero más específicamente, hay dos puntos que señalar al respecto.

\footnotetext{
${ }^{3}$ Especialmente en el Opus Majus dedicado a Clemente IV, y que fue editado por J. H. Bridges (Oxford, 3 vols. 1897-1900). La ciencia experimental que propone es superior a las demás porque engendra certeza completa, avanza donde las demás se detienen y no es relativa a ellas; de allí que incluso la presente como una ciencia transformadora.
}

Medievalia 50, 2018, pp. 299-314 
A.II.1 Uso metafórico del lenguaje descriptivo

Tal como ya vimos, la recurrencia a la interpretación metafórica conducía al efecto de tratar el lenguaje descriptivo como simbólico. Esto implica que cada nombre (de cada cosa) tiene simultáneamente varios significados, y todos son igualmente descriptivos, aunque en diversos planos de significación. Este punto es muy importante. Así, cuando un autor del siglo XII habla del fénix como símbolo de Cristo o de la serpiente como símbolo de Satán; Cristo y Satán se consideran realmente mencionados en cuanto objetos del universo, tanto como el ave o la serpiente, sin que importe que "fénix" no tiene correlato empírico conocido y "serpiente" sí. En otros términos, la descriptividad de la metáfora no es asunto de constatación empírica, ni el uso metafórico de un lenguaje descriptivo se considera incorrección semántica.

304 Veremos en el siguiente apartado cómo esta mezcla familiar de descriptividad y metáfora permitió introducir ampliaciones lingüísticas por esta vía.

\section{A.II.2 Valor descriptivo del lenguaje metafórico}

Esta variante es el reverso lógico de la anterior. Así como cada nombre descriptivo podía funcionar metafóricamente como descriptivo de otra realidad indirectamente mencionada, así también la metáfora como operación mental tenía una función descriptiva y no sólo alusiva. Hay un caso muy especial de derivación de la metáfora al razonamiento y es la analogía. Desde el punto de vista lingüístico, la construcción de metáforas implica un razonamiento analógico proporcional. Naturalmente este tipo de deducciones es aceptado como válido incluso por metodologías científicas restrictivas (exigentes) como la aristotélica, pero a condición de que el fundamento de la construcción analógica fuese esencial (es decir, que se tomara por objeto una nota esencial). La escolástica posterior llamó "intrínseca" a este tipo de analogía de proporción (o relación). Pero la metáfora es precisamente un caso distinto porque opera con notas accidentales (por ej. la "risa" del prado). De hecho, la metáfora tiene su gran lugar en la poesía y difícilmente cumplirá los recaudos epistemológicos de una disciplina descriptiva. El Alto Medioevo se sirvió de la analogía metafórica de una manera diferente, insistiendo más en los aspectos relacionales que en los descriptivos. Tal es el caso de la caracterización del hombre como microcosmos. Es decir, se postuló una relación de isomorfía entre un elemento conovido (o más conocido) y otro elemento no conocido (o menos conocido). Este tipo de procedimientos llevó a exageraciones puntuales, cuando se trató de buscar equivalentes exactos, pero sin duda favoreció el progreso de un pensamiento relacional que iba a ser imprescindible para la constitución de la nueva metodología científica. 


\section{B. INCORPORACIÓN DEL CORPUS MÉDICO}

Como indiqué, el proceso de asunción del corpus médico greco-árabe incluye dos momentos fundamentales: las traducciones y los comentarios. En ambos casos podemos apreciar ese fenómeno de ampliación lingüística que constituye un pilar fundamental de la nueva metodología.

Digamos previamente algo acerca de la concepción altomedieval de la enfermedad y la salud. Desde la época patrística, la tendencia a interpretar todas las realidades y fenómenos en términos religiosos, llevó a considerar la enfermedad en paralelo al pecado y la salud en términos de salvación. Entre los nombres de Cristo, el de Taumaturgo le fue aplicado con bastante asiduidad, como que correspondía perfectamente a su propia acción en el mundo (curaba a los enfermos y resucitaba a los muertos). Esta interpretación vinculante, por lo demás, tenía una larga tradición en el judaismo, como lo muestran el Libro de Job y algunos salmos.

Expresada en términos de analogía proporcional (metafórica) esta relación "terapéutica" sería:

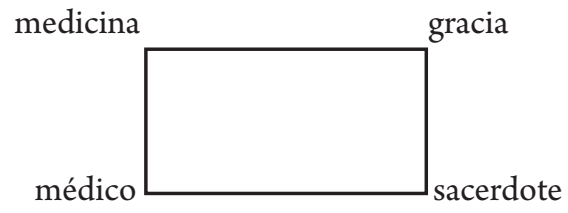

Esto es: la gracia es una medicina del alma, administrada por el sacerdote (Cristo) en función de médico. La adscripción a los miembros iniciales de los caracteres teológicos de la segunda copla nos da una visión de la medicina derivada de esta analogía:

$\rightarrow$ La salud es un estado de la naturaleza radicalmente "defectible", en el sentido de que puede perderse y no recuperarse por las solas fuerzas naturales (como la inocencia original).

$\rightarrow$ La enfermedad no es un estado natural sino contranatural (como el pecado) que siempre pone en peligro la continuidad existencial del individuo y en cuanto tal estado es siempre negativo y debe atacarse (analogía con el pecado que debe purgarse).

$\rightarrow$ La salud perdida a causa de la enfermedad puede recuperarse por una intervención extrínseca regenerativa (el medicamento análogo a la gracia) pero que debe ser administrado con competencia y de acuerdo con la naturaleza del mal (función terapéutica análoga a la sacerdotal). 


\section{B.I Las traducciones}

Es sabido que las traducciones plantearon múltiples problemas cuya vacilante solución determinó en definitiva una renovación del lenguaje técnico en la filosofía y la ciencia. Los traductores del siglo XII, formados en la tradición platonizante y carentes de recursos lingüísticos suficientes, recurrieron a varias estrategias para solucionar los problemas.

\section{B.I.1 La transliteración}

Cuando no se sabía el significado de un término técnico y por ende no se podía buscar el correlativo en la lengua traductora, se recurría a transliterar, creando un neologismo, que a partir de su difusión pasa a ser un término técnico nuevo, independientemente de la posible existencia de un equivalente anterior. Guy Beaujouan ("Fautes", 146-150) ha señalado varios casos en la traducción del Canon de Avicena realizada por Gerardo de Cremona. ${ }^{4}$ El neologismo de transliteración es una ampliación lingüística que implica la aceptación del carácter convencional y construido del lenguaje, al menos en algunos de sus aspectos, que son precisamente los que más importan a la ciencia. Así se articula lentamente la idea de la formación de un lenguaje artificial distinto del lenguaje natural, cuya descriptividad está más claramente pautada ya que cada término corresponde a una definición precisa.

\section{B.I.2 La metáfora}

Entre los recursos lingüísticos de los traductores aparece el proceso de incorporar un nuevo sentido a una palabra según las reglas de la analogía metafórica; es decir, hay una ampliación del significado de un término que metafóricamente pasa a designar una realidad de algún modo nueva o antes desconocida y por tanto innombrada. La razón de este proceder es la necesidad de adecuar el lenguaje descriptivo a las necesidades observacionales. El lenguaje científico consta mayoritariamente de nombres comunes o universales (en su porción nuclear) y los enunciados ocasionales (descriptivos concretos de circunstancias de tiempo y lugar o referencias a objetos singulares con nombre propio o pronombre demostrativo) funcionan como ejemplos de los enunciados universales. Una ampliación descriptiva del lenguaje científico como tal sólo puede hacerse en su porción de nombres generales, ya que un aumento de

\footnotetext{
${ }^{4}$ Señala concretamente casos del Libro III, fen. 1 tract. 1, cap. 3 y tract. 3, cap. 1. En la terminología filosófica ousia (del griego) y quidditas (del latín) son transliteraciones convertidas en términos técnicos capitales del escolasticismo moderno.
}

Medievalia 50, 2018, pp. 299-314 
enunciados circunstanciales no es de por sí un aumento de conocimiento científico. Cuando la investigación científica incorpora un conocimiento referido a una realidad innominada, la adecuación entre lenguaje científico y realidad requiere una modificación lingüística con la introducción de nuevos nombres comunes. Así como la creación de una nueva palabra (neologismo) cumple esta función, también sirve la ampliación metafórica de sentido de una palabra ya existente. La diferencia es que el neologismo introduce un término nuevo, y la metáfora amplía el significado de uno ya existente, es decir, formula una distinción conceptual en la palabra. Entonces tendremos un sentido vulgar (el inicial) y un sentido técnico de un vocablo, y el lenguaje descriptivo resultante será más rico que el anterior porque permitirá más referencias.

Los traductores medievales usaron el recurso metafórico de las "palabras-imagen", donde al significado inicial imaginativo se le añade por comparación el nuevo significado. ${ }^{5}$ Mientras que la transliteración es un recurso de descarte (en este aspecto no coincide con la creación voluntaria de neologismos por parte de los traductores modernos), la metáfora es un procedimiento escogido y considerado válido como expresión del conocimiento científico.

\section{B.I.3 El neologismo}

Este recurso fue de menor importancia cuantitativa que los otros, entendiéndolo en un sentido estricto de formación voluntaria y razonada de un nuevo vocablo a partir de los elementos reconocidos en la palabra por traducir. En cambio la transliteración, cuya función era simplemente indicar una palabra no comprendida (o no traducida) fue de hecho la mayor generadora de neologismos durante los dos siglos de incorporación del corpus greco-árabe. ${ }^{6}$

\section{B.II Los comentarios}

La novedad de los textos recibidos y la dificultad de comprensión en parte debida a estas particularidades lingüísticas, hizo necesaria una presentación aclaratoria y completiva de las obras. Además de los comentarios específicos de las obras médicas, debemos señalar los diccionarios que trataban de poner

${ }^{5}$ Cf. Beaujouan, con algunos ejemplos, como el de designar "ranula" a un tumor sublingual que modifica desagradablemente la voz ("Fautes", 148).

${ }^{6}$ No siempre estos recursos solucionan problemas, a veces crearon otros nuevos, como la asignación de una misma palabra a dos cosas distintas, o la confusión derivada del empleo de la imaginación personal del traductor. La zoología y la botánica presentan los más altos casos de confusión por este motivo (cf. Stannard, "Medieval reception").

Medievalia 50, 2018, pp. 299-314 
cierto orden en la maraña lingüística derivada de los procedimientos erráticos de los traductores. La función principal de estas obras, por ej. la clavis sanationis de Simón de Gênes, es establecer sinonimias a partir de una definición unívoca del concepto científico. Pero indirectamente producen un nuevo tipo de argumentación científica, no observacional ni propiamente médica, sino argumentativa, al justificar o refutar sinonimias e identificar el concepto subyacente (técnico) en un neologismo o transliteración. Esta modalidad, que al principio fue producto de una necesidad circunstancial (la coexistencia de pluralidad de criterios traductores) derivó — a mi modo de ver- en un hábito estereotipado a partir del siglo XIV, cuando el proceso de traducción, que había sido su origen, estaba modificado sustancialmente con la introducción de traducciones directas, y ya no era tan necesario. El carácter argumentativo del discurso médico escolástico no tiene sin duda sólo este origen, pero sí creo que es una de sus causas.

Otro aspecto novedoso a principios del siglo xIII es la aproximación del discurso médico al discurso físico, cosa que por cierto no es novedad absoluta en la historia de la medicina (ya Galeno se había referido a la semejanza entre la atracción del imán y la acción de los medicamentos, idea que sin duda es la fuente de los árabes que cita el Lincolniense), pero sílo es en algunos centros latinos que fueron pioneros de la nueva metodología científica.

Ilustraré este aspecto poco conocido con el caso de las referencias médicas del Comentario a la Física aristotélica de Roberto Grosseteste, cuya redacción ha sido fijada por su editor R. E. Dales entre 1228-1229.

El Commentarius in Octo Physicorum no es una explicación didáctica que siga el texto de corrido, como el comentario de Tomás de Aquino, sino una lectura estructural tratando de determinar las llamadas "conclusiones científicas”, o sea los núcleos o proposiciones fundamentales de la física. La fijación de esta tesis daría como resultado un sistema dentro del que se desarrollarían los estudios puntuales para los cuales el Lincolniense propone su famosa metodología de la resolutio-compositio con matematización de los resultados. Está claro que la física constituye para Grosseteste el marco general de todo sistema científico observacional, y por tanto el modo de abordaje de estos fenómenos proporciona un modelo válido para toda otra aproximación sistemática a los problemas científicos. Este es un temprano ejemplo de la elaboración de un sistema del conocimiento médico integrable en el marco epistemológico aristotélico. Grosseteste no era médico ni se ocupó especialmente de cuestiones terapéuticas. Los ejemplos que enuncia están tomados de las obras que conoció y por tanto no aporta propiamente nada a la ciencia médica de su tiempo. Lo que nos interesa ver es el procedimiento metodológico de 
ampliación del lenguaje a partir de esta aproximación a modelos de la física aristotélica, concretamente por aplicación del uso metafórico.

En el comentario al Libro VII se aprecia una visión de la acción terapéutica como un caso subsumible en la teoría general del acontecer físico, según la cual la terapia es una especie del movimiento cualitativo. Grosseteste propone allí cuatro principios generales de uso empírico (empíricamente constatable) de los conceptos aristotélicos:

$1^{\circ}$ Reducción de las cualidades sensibles a las basadas en el tacto, o sea, las derivadas de la cantidad y por tanto mensurables en cuanto a principios de interacción. Sin duda esto está en consonancia con su propuesta metodológica de cuantificar los resultados empíricos.

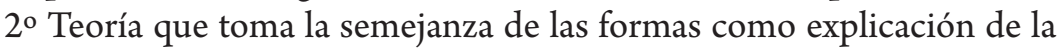
actividad de una sustancia sobre otra (especie de "homeopatía").

$3^{\circ}$ Consideración de la forma (natura) como principio mediato de la acción; el principio inmediato es la propiedad de la cual se deriva directamente la actividad.

$4^{\circ}$ Caracterización de la propiedad según la experiencia y no por derivación apriorística de la forma sustancial; por eso la forma dejará de tener significación como principio explicativo, pues de ella no puede concluirse nada.

En las consideraciones y ejemplos que acompañan a estos principios tenemos dos casos relativos a nuestro tema: 1) la explicación de la función terapéutica del medicamento por analogía con la atracción y 2) una generalización de la misma en el marco de la cinética aristotélica.

1. En el último párrafo del Comentario al Libro VII, refiriéndose a las relaciones de motor y móvil, y a propósito de la afirmación de Averroes (que él acepta) de que no hay medio entre el motor próximo y el móvil, pone el ejemplo del imán y el hierro. Concluye:

Pues la aguja unida al imán [por frotamiento y que luego atrae a otra aguja] adquiere un acto proporcionado a la potencia que antes tenía; y esta disposición es de toda la sustancia, la cual según Avicena (Libro I sobre lo comestible y lo bebible) es cierta propiedad que adviene a la complexión de la materia dispuesta a tal recepción (Grosseteste, Commentarius, 130). ${ }^{7}$

7 "Acus enim coniuncta cum adamante adquirit actum similem potencie quam ante habebat, et hec comparacio est a tota substancia que secundum Avicennam primo libro sui de 
Aquí importa la generalización asumida, que le permitirá aplicar el principio a casos diferentes como las sustancias inorgánicas y las vivientes, combinando la idea de la semejanza formal ( $2^{\circ}$ principio) con la de inmediatez de la propiedad ( $3^{\mathrm{er}}$ principio):

Y esta disposición o propiedad algunas veces se relaciona a la acción, como en el caso del imán y del medicamento que atrae, y otras veces a la recepción, como en el caso del hierro y el humor. Esta operación de la forma específica a la cual acompaña o sigue y según ella se denomina a toda la sustancia o especie. Tampoco se deriva esta operación de la forma específica en sí misma, sino de la propiedad inherente, así como el imán no atrae por ser imán sino por una propiedad que es inherente a esta forma. Y dice Avicena en el Libro V de los Cánones: la tríaca no expele al veneno por la forma, sino por su propiedad, que es confortar al corazón [...]. Y así sucede con la medicina [antídoto] extrínseca que libra del veneno y otras cosas (Grosseteste, Commentarius, 130). ${ }^{8}$

Vemos en este párrafo una extensión analógica del concepto físico de "atracción”, cuyo referente adecuado inmediato es el imán, a la función terapéutica del antídoto, estableciéndose la relación metafórica.

eo quod comeditur et bibiut, est quedam propietas advenins post complexionem in materia disposita ad ipsius suscepcionem". La cita de Avicena corresponde a Canon, Lib. F, fen. 2, doctr. 2, summa 1, cap. 15: "de his, quae proveniunt ex his, quae comeduntur et bibuntur". En el texto se traduce adama (literalmente "diamante") por "imán" (en latín magnes) para mayor claridad, pues ese es el sentido del texto. La razón de usar adamas por parte de Grosseteste, es que los antiguos y medievales atribuían a esta piedra virtudes atractivas y por tanto se tomaba al diamante como un caso típico de imán (v. por ej. Tomás de Aquino, De anima, Q. ún. art. 1c.).

8 "Et hec disposicio aut propietas aliquando est ad agendum ut in adamente et medicina attrahente aliquando ad paciendum et in ferro aut umorer. Et hec operacio ex forma speciei tocius quam comitatur proprietas aut sequitur et propter hoc vocatur tota substancia vel tota species, nec sumitur operacio hec a forma specifica secundfum se sed a propietate inherente, sicut magnes non attrahit quia magnes sed propter proprietatem que inest illi forme. Et avicenna quinto Cannonis: tiriaca non expellit venenum per formam sed per proprietatem, que est comfortarie cor [...]. Et sic est de medecina liberante a veneno extra posita, et ita de aliis". Dales identifica el siguiente texto de Avicena mencionado por Grosseteste: "Et [theriaca] non efficit has operationes nisi propter proprietatem formae ejus, sequentem complexionem simplicium ipsius, ita ut confortet spiritum ..." (Lib. V, ed. Venecia 1555, f. 522 V).

Medievalia 50, 2018, pp. 299-314 


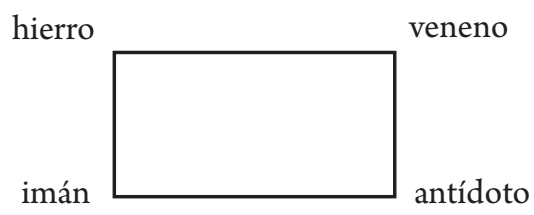

Lo importante es que esta analogía tiene sentido real y descriptivo (no es sólo alusión, como en la poesía) y entra a jugar en el marco deductivista de la epistemología aristotélica, aunque inicialmente no pertenece a ella. En efecto, para Aristóteles el modelo de conocimiento científico es el que procede del silogismo apodíctico, sobre todo en sus modos directos. El razonamiento por analogía introduce implícitamente un condicional en relación al segundo miembro (la conclusión en la disciplina médica) ya que asume como verdadero el primer miembro (el de la física) que no pertenece al sistema. En estricto aristotelismo este tipo de deducción científica no puede tener igual garantía de certeza que las otras. Me parece que si un autor decididamente crítico en materia metodológica como el Lincolniense lo da por bueno es porque en el fondo piensa todavía con las categorías mentales del siglo anterior, y para él el funcionamiento analógico resulta evidente y cierto.

2. La atracción es un movimiento peculiar pero reductible a una teoría general del movimiento, que incluye la comparación, la relación y la composición de movimientos. En realidad Grosseteste no parece haberse interesado mucho en los detalles presentados por Aristóteles en la segunda parte del Libro VII, ya que a su juicio todo se reduce a una proposición o conclusión afirmando la compatibilidad del movimiento. ${ }^{9}$

A propósito de este tema introduce un ejemplo médico:

La medicina tríaca opera de dos modos: o por calor o por propiedad. Con respecto a las que operan con calor, dice Avicena que tienen una propiedad que mueve a la humedad fuera del lugar en el cual se aplica, como es claro en los fomentos y semejantes. En el caso del medicamento que atrae por la propiedad, atrae por la semejanza que tiene con aquello que atrae, así como los tejidos atraen alimento que les es propio y conveniente. Por esta vía la medicina soluble atrae al humor específico. Y los medicamentos que liberan de un veneno extrínseco atraen el veneno mortal introducido; así es como el

\footnotetext{
${ }^{9}$ Corresponde a Bk 348 a 10ss. "Dubitabit autem aliquis utrum omnis comparabilis aut non [... ostendit quis motus cui motui comparatur et quis non” (Grosseteste, Commentarius, 128).
} 
aceite de escorpión y la grasa de cocodrilo alimentan su veneno y sin embargo liberan del veneno corrompiéndolo, como el medicamento frío corrompe al veneno cálido y a la inversa; y expeliendo como la tríaca conforta al corazón, y el corazón reconfortado contrario al veneno lo expele antes que llegue hasta él mismo. Si los medicamentos atractores tienen la propiedad de la calidez atraen mejor, y cuanto más cálidos son, son más fuertemente atractores, porque aúnan dos causas de atracción: la propiedad y el calor que es auxiliar suyo. Y si lo alimentado es más fuerte que el alimento que lo transforma en su misma natura y a la inversa. Y sucede que la planta que es mortífera en tierra de los persas, trasplantada a Egipto dejó de ser nociva. La umea trasplantada de un lugar a otro cambia de sabor. Así es que los imanes son asemejantes al hierro en potencia, porque la sola potencia del imán es una forma de hierro con poder que atrae al hierro (Grosseteste, Commentarius, 130). ${ }^{10}$

10 "Motiva triaca operatur duobus modis, aut in caliditate aut a proprietate. Et de his que operantur a caliditate dicit Avicenna quod habent proprietatem quod moveant humiditatem a loco cui obviant, ut patet in euplaustris et in aliis. In medicina que trahit a proprietate attrahit per similitudinem quam habet ad illud quod attrahit, sicut membrana attrahunt cibum sibil proprium et convenientem. Et per illam viam trahunt medicine solutive humorem sibi proprium. Et quedam medicine liberantes a veneno extra posito trahunt venenum mortiferum intrapositum, sicut olium scorpionis et adeps cocogrili venenum suum alit et tamen liberatur a veneno; scilicet corrumpendo, sicut medicina frigido corrumpit venenum calidum et econverso; et expellendo, sicut tiriaca comfortans cor, et cor comfortatum contrarium est veneno, et ipsum expellit antequam veniat ad ipsum cor. Sed si medicine attractive a proprietate sunt calide, trahunt melius et quando calidiores tante sunt attractive a proprietate sunt calide, trahunt melius et quando calidiores tante sunt attractive forciores quia habet duas causas attraccionis, scilicet proprietatem et caliditatem que estei auxiliatrix et si nutritum est forcius nutricione, ipsum convertit in naturam suam et converso. Et accidit quod planta que fuit mortifera in terra persarum, trasplantata in Egypto fuit absque nocuitate. Et humea trasplantata de loca ad locum fit alterius saporem. Sic est quod magnes cum sint similes ferro potencia, quia tantum virtutis magnetis est forma feri virtute trahit ferrum”. La mención a Avicena corresponde al Liber Canonis de Medicinis Cordialibus (cit.) Lib. VI, fen. 6, tract. 3. Por otra parte, esta referencia analógica del alimento y la imantación la repite Averroes en este mismo paso de su Commentum in Libros Physicorum Aristotelis y casi con las mismas palabras de Grosseteste (Commentarius, 120, nota c: "Et similiter oportet hic intelligere hoc de motu ferri ad magnetem et nutrimenti ad membra $[. .$.$] nutrimenti non moventur ad nutriendum$ nisi cum fiut in aliqua qualitate de magnete [...]”) ¿Se inspiró Grosseteste en este pasaje? Es muy posible, porque cita expresamente las dos líneas anteriores a lo transcrito sobre la inexistencia de medio entre motor y móvil; pero sin duda le da un sentido más amplio y más concreto, no sólo por la mayor extensión textual, sino porque Grosseteste, a diferencia de Averroes, comenta selectivamente y aumenta de su propia reflexión las proposiciones centrales del sistema. El hecho de dedicar un espacio comparativamente extenso al asunto es al menos prueba de un interés especial.

Medievalia 50, 2018, pp. 299-314 
Vemos aquí una explicación de una acción terapéutica en términos de distinción y composición de movimientos, y también la aplicación ejemplificativa del principio que fundamenta la acción inmediatamente en la propiedad. El tema físico que está considerado es la posibilidad de comparar movimientos entre sí, y estos ejemplos pueden tomarse como una prueba inductiva, pero faltaría el paso esencial de la generalización. Para que el ejemplo del medicamento empalme bien con el texto aristotélico correspondería primero mostrar cuáles movimientos son comparables y cuáles no; precisamente la falta de este paso - lo que no podía escapar a Grosseteste- muestra que la conexión de temas no es directa. Pienso más bien que la tesis física de la compatibilidad y comparabilidad de movimientos le sirve para reflexionar análogamente sobre el modo operativo de algunas sustancias que producen determinados movimientos (como la sanación, movimiento en el género de cualidad). Esta analogía tiene varias puntas: la estructura similar a la cinética, la acumulación de potencias o virtualidades y el principio inmediato en la propiedad específica. Parte de un concepto médico: las medicinas (en nuestro caso los antídotos) operan por calor o por semejanza de la propiedad específica. En cualquiera de los dos casos su acción tiene una estructura cinética análoga a sendos movimientos físicos. Estos modos medicinales son independientes y cada uno puede producir el resultado. Cuando las dos propiedades coexisten en una medicina, sus virtualidades o potencias curativas se acumulan y ésta resulta más eficaz. Esta acumulación es entendida análogamente a la composición de movimientos (en relación a los motores, conforme al pensamiento aristotélico).

Una medicina tiene una propiedad que produce una forma semejante a una disposición en el sujeto medicamentado de manera análoga a la imantación de una aguja que luego atrae al hierro. Por lo tanto, toda sustancia que tenga la propiedad indicada para un determinado efecto será apropiada, independientemente de toda otra consideración (cual sea su forma sustancial o las demás propiedades). Por tanto, propiamente "medicina" no es una sustancia sino una propiedad que pueden poseer varias sustancias y que produce por sí e inmediatamente el efecto curativo por semejanza o por atracción extrínseca. La consecuencia más importante, desde el punto de vista metodológico, que se deduce de esta postura, es que a la ciencia médica no le compete estudiar esencias sino propiedades curativas, puesto que de ellas se deriva el efecto terapéutico.

Aunque Grosseteste no lo explicita, está claro que propone una concepción peculiar y bastante interesante del medicamento. En primer lugar, lo reduce fisicalísticamente, al integrarlo en una teoría general del movimiento que — como la aristotélica — sin duda lo consiente. En segundo lugar, privilegia 
la indagación empírica de las propiedades específicas, lo que sin duda llevará a la idea de los "específicos", o sea, la especialización terapéutica de las sustancias curativas. Es evidente que el producto cambió en la farmacopea europea renacentista y supone un cambio en la mentalidad médica. No se trata de añadir nuevas sustancias curativas y este cambio no debe interpretarse como un aumento de posibilidades de recetar específicos (los médicos altomedievales, árabes y judíos, conocían probablemente tantas sustancias curativas, o poco menos, como los médicos bajo medievales). A mi juicio cambia el criterio y el fundamento de la acción de medicamentar, y ello independientemente de las teorías médicas sobre la salud y la enfermedad como propiedades del organismo. Está claro que si bien el viejo punto de vista del equilibrio interno seguirá presidiendo las explicaciones médicas sobre etiología de las dolencias, el proceso de sanación, punto esencial de la ciencia médica, se alteró a partir de un significativo ensanchamiento técnico y teórico del concepto de medicamento. Quizá hasta podríamos imaginar que aquí se halla una de las fuentes de la larga controversia sobre "el mejor medicamento" que hoy, siete siglos después, toma la forma de un torneo entre defensores de la homeopatía y la alopatía. Aunque los contextos sean diferentes, y desde luego las teorías esgrimidas sean inconmensurables, hay un punto común a esta preocupación y es la fijación del límite descriptivo y eficaz de una consideración holística de la sustancia.

\section{BIBLIOGRAFÍA}

Beaujouan, Guy, "Fautes et obscurités dans les traductions médicales du Moyen Age", Revue de Synthèse, 89, 1968, 145-152.

Gilson, Etienne, La filosofía en la Edad Media, t. 1, Madrid: Gredos, 1958.

Grosseteste, Roberto, Commentarius in VII Libros Physicorum Aristotelis, ed. de

R. E. Dales, Boulder: University of Colorado Press, 1963.

Migne, Jacques Paul, Patrología latina.

Stannard, Jerry, "Medieval reception of classical plant names", Revue de Synthèse, $89,1968,153-162$. 